\title{
Aplikasi Pengelolaan Dokumen pada Muat Kapal Berbasis Desktop (Studi Kasus: PT KSJM)
}

\author{
Dela Haeraini ${ }^{\mathrm{a} 1}$, Henny Hartono ${ }^{\mathrm{a} 2}$ \\ ${ }^{a}$ Departemen Sistem Informasi, Universitas Bunda Mulia \\ Jl. Lodan Raya No 2. Jakarta Utara \\ 1delahaeraini@gmail.com \\ 2hhartono@bundamulia.ac.id
}

\begin{abstract}
Abstrak
PT KSJM merupakan suatu bentuk lembaga yang bergerak di bidang jasa pengangkutan umum yang menggunakan transportasi laut, yaitu kapal yang di dalamnya terdapat kegiatan untuk memberikan jasa. Penelitian ini dilakukan untuk memberikan solusi terhadap permasalahan yang terjadi dalam proses bisnis yang dimiliki oleh PT KSJM. Tujuan penelitian adalah untuk menghasilkan aplikasi pengelolaan dokumen yang dapat menggabungkan proses yang ada di PT KSJM dengan data yang terkait. Penggabungan dilakukan agar meningkatkan efisiensi dalam hal ini, yaitu sumber daya yang digunakan oleh pihak perusahaan serta memfasilitaskan media penyimpanan data yang terstruktur. Hasil dari penelitian ini adalah aplikasi pengelolaan dokumen yang dibuat memiliki modul yang dapat menyimpan unggahan DO, pengentrian data barang yang akan dimuat, pencatatan dan pencetakan faktur, serta memiliki modul yang dapat memberikan informasi untuk PT KSJM seperti daftar data klien dan data kapal.
\end{abstract}

Kata kunci: aplikasi, pengelolaan dokumen

\section{Desktop-Based Document Management Application on Shiploading (Case Study: PT KSJM)}

\begin{abstract}
PT KSJM is an institution engaged in public transportation services that uses sea transportation, namely ships in which there are activities to provide services. This research was conducted to provide solutions to problems that occur in business processes owned by PT KSJM. The research objective is to produce a document management application that can integrate existing processes in PT KSJM with related data. This integration is carried out to improve efficiency in terms of resources used by the company and to provide structured data storage media. The result of this research is a document management application that has a module that can store DO uploads, data entry of goods to be loaded, recording and printing of invoices, and has a module that can provide information for PT KSJM such as client data lists and ship data.
\end{abstract}

Keywords: Keyword_1, Key_2 (2 to 6 Keywords)

\section{Pendahuluan}

Teknologi informasi merupakan faktor pendukung yang efektif untuk perusahaan dalam menunjang aktivitas sehari-hari dalam berbisnis [1]. Salah satu teknologi komputer yang berkembang ialah aplikasi berbasis desktop. Aplikasi desktop yang terkomputerisasi merupakan alternatif yang paling cocok untuk menyiasati persiapan segala data yang akurat dan memiliki tingkat keamanan yang terjamin dan perusahaan dapat dengan mudah beroperasi secara offline (tanpa adanya internet).

Perkembangan yang terjadi pada kemajuan teknologi merupakan fakta yang paling menarik dalam kemajuan teknologi yang terjadi pada saat ini. Salah satu bidang yang boleh dibilang fenomena dalam perkembangan ini yaitu aplikasi pengelolaan dokumen. Dengan adanya aplikasi pengelolaan dokumen ini memudahkan perusahaan untuk melakukan pengunggahan dokumen, pengentrian, pembuatan faktur, serta laporan.

PT KSJM merupakan perusahaan yang bergerak di bidang jasa pengangkutan umum yang menggunakan transportasi laut, yaitu kapal. PT KSJM menerima order (berupa dokumen DO) dari klien dan selanjutnya PT KSJM membuat packing list (PL). PL merupakan suatu dokumen pengemasan yang menunjukkan jumlah, jenis, serta berat dari suatu barang yang akan dikirim. Dari PL perusahaan dapat menentukan faktur yang akan dikeluarkan untuk klien. Fakur merupakan dokumen yang akan dikeluarkan perusahaan, yang dijadikan bukti yang isinya jumlah biaya yang harus dibayar oleh klien.

Dalam proses bisnisnya, PT KSJM masih menggunakan proses konvensional dalam pembuatan PL, 
dan faktur, serta belum adanya pengarsipan yang aman dalam menyimpan DO. Pembuatan PL yang masih menggunakan Ms.excel dan faktur masih menggunakan Ms. Word di mana belum terdapat aplikasi yang dapat menyimpan unggahan DO, membantu dalam mengentri data barang yang akan dimuat, serta membuat dan mencetak faktur.

PT KSJM membutuhkan penerapan aplikasi pengelolaan dokumen yang penting untuk perusahaan karena dengan adanya aplikasi dapat membantu dalam penyimpanan unggahan DO, pengentrian data-data terkait barang yang dimuat, pembuatan dan pencetakan faktur serta dapat meningkatkan pengelolaan data-data agar lebih aman dibandingkan dengan proses pengelolaan data secara konvensional.

Berdasarkan dari beberapa penelitian yang sudah ada, penerapan aplikasi berbasis desktop telah bekerja dengan baik untuk suatu perusahaan dalam menjalankan proses bisnisnya. Salah satu penelitian tentang penerapan aplikasi berbasis desktop dalam rancangan bongkar muat barang [2], memiliki hasil mampu mempermudah proses perekapan data bongkar muat serta proses pencarian data. Dari penelitian yang sudah ada menunjukkan bahwa penerapan aplikasi berbasis desktop mampu menghasilkan aplikasi yang sesuai dengan kebutuhan. Pada penelitian ini akan menerapkan aplikasi pengelolaan dokumen, di mana aplikasi tersbut berbasis desktop yang dapat membantu pihak perusahaan dalam menyimpan unggahan DO, pengentrian data-data terkait barang yang akan dimuat, pembuatan dan pencetakan faktur.

\section{URAIAN PENELITIAN}

\section{A. Pengiriman}

Pengiriman merupakan suatu bagian yang penting dalam rantai persediaan yang berfungsi untuk menyiapkan dan mendistribusikan barang ke klien. Pengiriman pasti menggunakan transportasi, di mana transportasi yang diharapkan agar efektif dan efisien, baik dari sisi biaya, kecepatan pengiriman dan ketepatan waktu sehingga hal ini berhubungan dengan model transportasi apa yang dipakai [3].

Dalam jasa pengiriman barang ada yang melalui jalur darat, laut, dan udara. Ekspedisi Muatan Kapal Laut (EMKL) merupakan usaha pengurusan dokumen dan muatan yang akan diangkut melalui kapal. Untuk melakukan pengurusan ini, EMKL mendapat surat kuasa dari pemilik muatan untuk mengurus barangnya. Di pelabuhan muat, EMKL membantu pemilik barang dalam hal membukuan muatan pada agen pelayaran, dan instansi terkait lainnya dan membawa barang dari gudang pemilik barang ke gudang di dalam pelabuhan [4]

\section{B. Jasa Pengiriman Barang Kapal}

Pengiriman barang merupakan suatu usaha yang dilakukan secara individu atau kelompok dalam suatu bisnis untuk dapat memberikan jasa berupa pengiriman barang, baik antar negara, antar pulau, ataupun antar kota [5].

Dari definisi di atas dapat disimpulkan bahwa jasa pengiriman barang merupakan seluruh aktivitas yang harus dilakukan untuk mengirim barang sampai pada orang yang namanya tercantum di dalam berkas/sesuai dengan permintaan klien.

\section{Delivery Order}

Delivery Order (DO) bila diartikan ke dalam bahasa Indonesia adalah pengantar pesanan atau biasa disebut surat jalan. DO merupakan surat berpergian di mana DO digunakan sebagai surat pengantar barang ke klien [6]. Perihal yang diperlukan di jalan raya mulai dari keluar perusahaan sampai memasuki wilayah klien terdapat dalam DO/surat jalan yang memiliki kekuatan hukum. Di dalam DO/surat jalan tercantum nama perusahaan, alamat perusahaan, nomor DO, jenis barang dan kuantitas yang akan dipesan oleh klien.

\section{Packing List}

Packing List merupakan nota atau faktur yang isinya jumlah dan berat barang (termasuk berat bersih dan berat kotor). Packing List merupakan dokumen yang dibuat oleh pihak exportir atau importir [7]. Data-data yang ada di dalam packing list biasanya terdiri dari:

- Nama pengirim atau exportir

- Penerima barang atau pembeli

- Nomor packing list

- Tanggal

- Jumlah barang

- Nama barang

- Jumlah

- Nama kapal

- Tanggal keberangkatan

\section{E. Faktur}

Faktur adalah klaim terhadap organisasi pembeli. Biasanya hal tersebut menunjukkan nomor pesanan dan harga barang. Prosedur pembersihan faktur tidak seragam [8].

\section{F. System Development Life Cycle (SDLC)}

SDLC merupakan proses bagaimana memahami suatu sistem informasi dapat membantu kebutuhan bisnis dengan cara merancang suatu sistem, membangun sistem tersebut, dan mengirimkannya kepada pengguna agar dapat digunakan untuk kebutuhan bisnisnya [9]

Metodologi backbone dasar untuk pengembangan kustom adalah siklus hidup pengembangan sistem (SDLC) [10]. SDLC merupakan kerangka kerja terstruktur tradisional, digunakan untuk proyek-proyek TI besar, yang terdiri dari proses sekuensial di mana sistem informasi dikembangkan.

Kelebihan SDLC antara lain: menegakkan kualitas dengan mempertahankan standar, memampukan para analis dan desainer sistem secara sistematis melalui setiap langkah dalam proses terstruktur, serta memiliki kemungkinan lebih rendah kehilangan masalah penting dalam mengumpulkan persyaratan pengguna.

\section{G. $B P M N$}

SDLC merupakan seperangkat bentuk dan simbol standar yang digunakan untuk mewakili peristiwa, proses, 
dan alur kerja dalam alat pemodelan berbasis komputer [11].

Secara singkat, proses bisnis merupakan susunan tugas yang berhubungan secara logis yang akan menghasilkan hasil bisnis tertentu, seperti pengiriman pesanan yang tepat kepada pelanggan atau memberikan produk inovatif ke pasar. Pada proses bisnis biasanya melibatkan bidangbidang yang fungsional, komunikasi dan koordinasi pekerjaan, pengetahuan, serta informasi.

BPM (Business Process Management) merupakan pendekatan bisnis yang bertujuan untuk terus meningkatkan dan mengelola proses bisnis [12]. Menganalisis proses yang ada, merancang proses baru, dan mengoptimalkan proses tersebut merupakan metodologi dan berbagai alat yang difasilitasi oleh Manajemen Proses Bisnis (BPM).

BPM mendokumentasikan serta memantau proses bisnis untuk dapat membantu perusahaan mengidentifikasi efisiensi dalam penggunaan perangkat lunak agar terhubung dengan masing-masing sistem yang dipakai perusahaan dalam proses tertentu untuk mengidentifikasi titik-titik masalah.

Dalam BPMN, Proses Bisnis menggambarkan apa yang dilakukan oleh suatu organisasi (cara kerja) untuk mencapai tujuan tertentu [13].

\section{H. Pengujian Sistem}

Pengujian sistem merupakan komponen sistem terintegrasi untuk membuat sistem yang lengkap. Proses ini berkaitan dengan menemukan kesalahan yang dihasilkan dari interaksi yang tidak terduga antara komponen dan masalah antarmuka komponen.

Pengujian juga berkaitan dengan menunjukkan bahwa sistem memenuhi persyaratan fungsional dan nonfungsional, dan menguji sifat-sifat sistem yang muncul. Untuk sistem besar, ini mungkin proses multi tahap di mana komponen- komponen diintegrasikan untuk membentuk sub sistem yang diuji secara individual sebelum sub sistem ini diintegrasikan untuk membentuk sistem akhir.

Dalam pengujian unit ada beberapa macamnya, salah satunya UAT (User Acceptance Testing). UAT adalah singkatan dari pengujian penerimaan pengguna dan biasanya digunakan untuk merujuk pada pengujian perangkat lunak sebelum sistem informasi diperkenalkan ke suatu perusahaan sebagai pengujian pengguna akhir [14]. Salah satu tujuan UAT adalah untuk memastikan sistem baru yang akan dikenalkan akan melakukan apa yang sudah ditetapkan untuk dilakukan dan sudah sesuai dengan persyaratan yang dimiliki oleh bisnis tersebut.

\section{METODOLOGI}

Semua paragraf mesti di-indent. Semua paragraf mesti rata kiri dan rata kanan.

\section{A. Analisis Proses Bisnis}

Sesuai dengan pengamatan dan observasi yang dilakukan oleh peneliti, adapun gambaran proses bisnis yang berjalan pada PT KSJM adalah sebagai berikut:

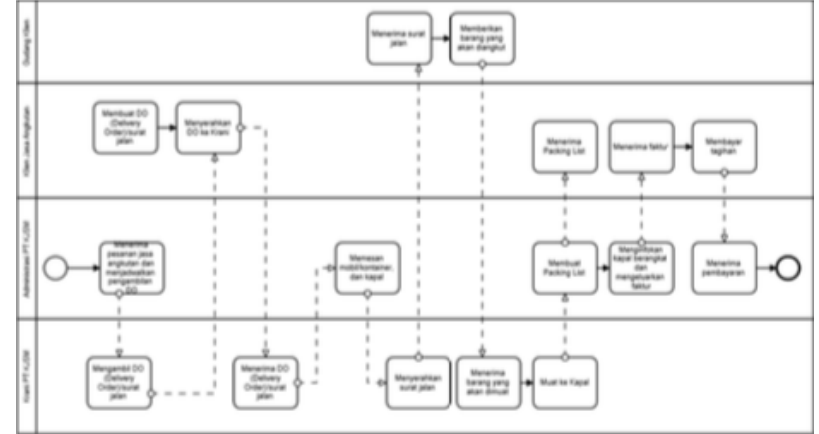

Gambar 1. BPMN PT KSJM

Berdasarkan Gambar 1, proses bisnis pada PT KSJM, dapat dijabarkan sebagai berikut:

PT KSJM menerima pesanan jasa angkutan, lalu krani mengambil DO dari klien sebagai permintaan untuk menggunakan jasa ekspedisi PT KSJM, setelah itu PT KSJM melakukan pemesanan kontainer, dan kapal. Setelah siap, maka PT KSJM mengambil barang yang akan dimuat dengan membawa DO/surat jalan tersebut lalu dimuat ke kapal.

Pembuatan PL dimulai setelah barang dimuat lalu diserahkan ke klien, klien menerima PL. Setelah itu PT KSJM menginfokan kapal berangkat dan mengeluarkan faktur kepada klien. Klien menerima faktur dan membayar tagihan, PT KSJM menerima pembayaran yang dilakukan oleh klien.

\section{B. Pengembangan Aplikasi}

Penelitian ini menggunakan metodologi pengembangan air terjun, disebut air terjun (waterfall) karena dilakukan berurutan fase demi fase yang dilalui harus menunggu fase sebelumnya selesai lalu lanjut ke fase selanjutnya [3]. Tahapan pengembangan perangkat lunak dengan waterfall meliputi: system requirements, software requirements, analysis, program design, coding, testing, dan operations [15]. Tahapan-tahapan waterfall yang ditunjukkan pada Gambar 2.

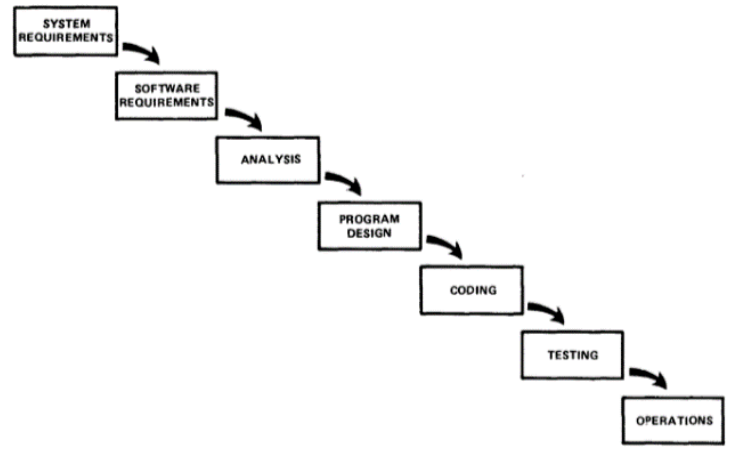

Gambar 2. Tahapan pada Waterfall

Berdasarkan Gambar 2 di atas, maka tahapan dalam metodologi pengembangan sistem waterfall adalah sebagai berikut : [15]

1) System requirements: layanan, kendala, dan tujuan sistem ditetapkan melalui konsultasi dengan 
pengguna sistem, lalu didefinisikan secara rinci agar berfungsi menjadi spesifikasi sistem.

2) Software requirements: Proses desain sistem mengalokasikan persyaratan untuk sistem perangkat lunak atau perangkat keras. Dalam hal ini membangun keseluruhan mengenai arsitektur sistem.

3) Analysis: Proses menganalisa mengenai hal-hal yang diperlukan dalam sistem, berdasarkan 2 tahapan sebelumnya.

4) Program design: Selama tahap ini, desain perangkat lunak direalisasikan sebagai perangkat program. Design aplikasi menggunakan UML sebagai alat bantu, dan design database menggunakan ERD.

5) Coding: Pada tahap ini menuliskan kode-kode menggunakan bahasa pemrograman. Pada penelitian ini menggunakan bahasa pemrograman visual basic.

6) Testing: Program digabungkan dan diuji sebagai sistem lengkap, pengujian dilakukan untuk memastikan bahwa persyaratan perangkat lunak telah disepakati sudah dipenuhi. Peneitian ini menggunakan pengujian dengan metode UAT.

7) Operation: Dalam tahap ini, merupakan tahapan terpanjang. Sistem diinstal dan digunakan secara praktis.

Penelitian ini dilakukan di PT KJSM. Data penelitian terbagi menjadi dua bagian yakni data primer yang diperoleh dari PT KJSM berupa data-data terkait pengelolaan dokumen terkait muat kapal dan data sekunder diperoleh berdasarkan hasil studi literatur tentang penelitian terkait.

Perancangan aplikasi pengelolaan dokumen berbasis desktop menggunakan program Visual Basic, terkoneksi dengan basis data MySQL serta menggunakan Crystal Report untuk menghasilkan laporan.

Tahapan penelitian menggunakan tahapan-tahapan dalam metodologi waterfall.

\section{HASIL DAN PEMBAHASAN}

\section{A. Implementasi}

Hak akses untuk aplikasi terbagi untuk super admin, admin, serta pimpinan.

Gambar 3 merupakan halaman login, halaman pertama yang ditampilkan saat menjalankan aplikasi pengelolaan dokumen. Halaman ini berfungsi sebagai bentuk validasi terhadap aktor untuk masuk ke halaman selanjutnya yang ada di dalam aplikasi.

Aktor yang dapat melakukan login hanya user yang sudah terdaftar dalam aplikasi, yaitu dengan tipe akun super admin, administrasi, dan pimpinan.

Halaman utama untuk setiap user ditampilkan pada Gambar 4, Gambar 5, dan Gambar 6. Input password diberikan karakter (*) sebagai bentuk pencegahan terhadap pencurian password yang tidak terduga. Tombol Batal berfungsi untuk keluar dari aplikasi.

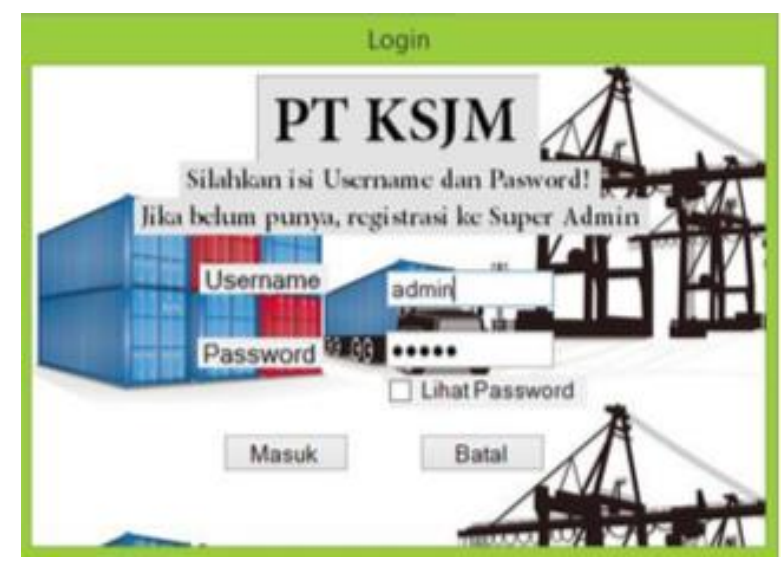

Gambar 3. Halaman login

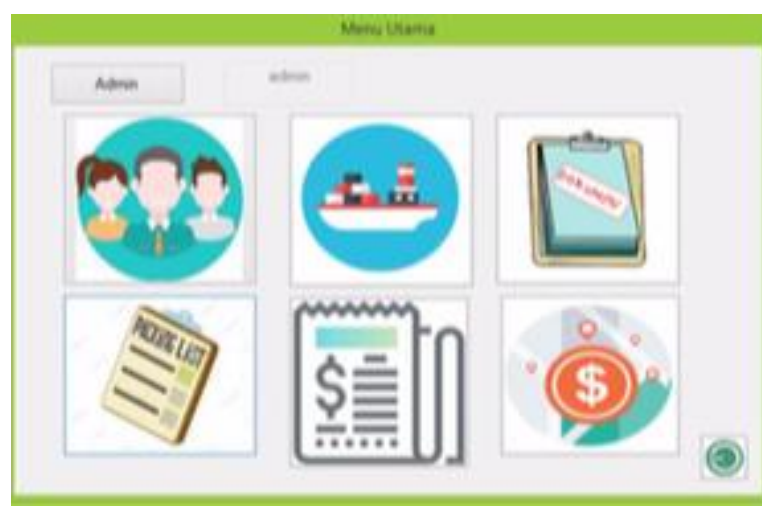

Gambar 4. Halaman home administrasi



Gambar 5. Halaman home pimpinan

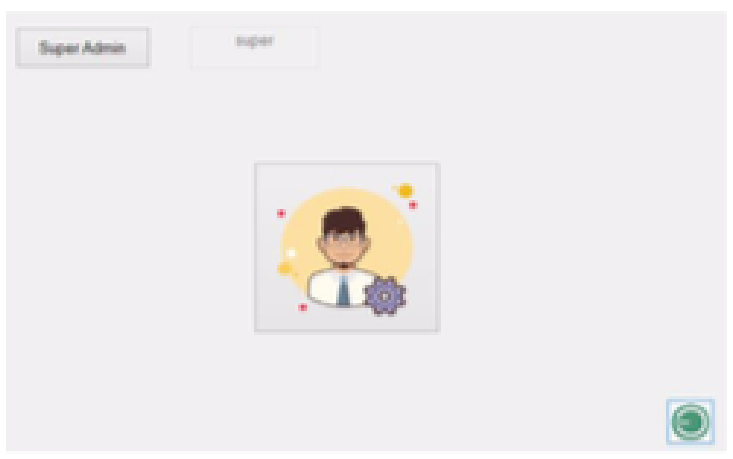

Gambar 6. Halaman home super admin

Pada Gambar 7 ditampilkan halaman input data kapal yang setelahnya menghasilkan laporan daftar kapal secara 
keseluruhan yang sudah diinput melalui halaman input data kapal.

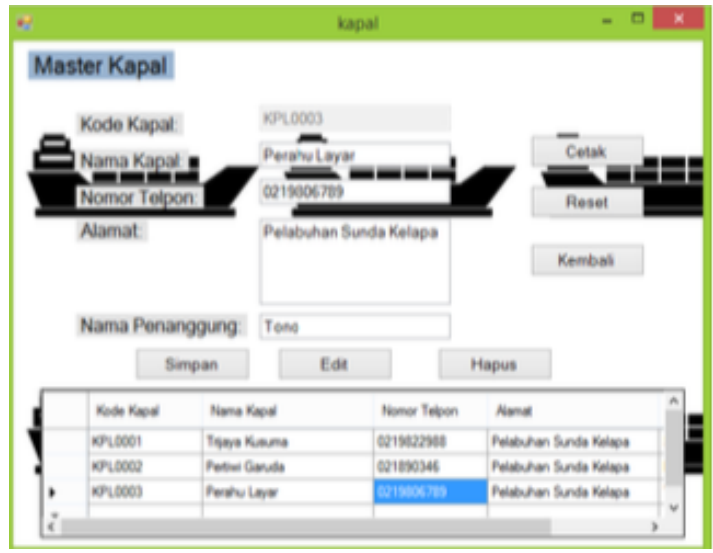

Gambar 7. Halaman input data kapal

Selanjutnya pada Gambar 8 merupakan halaman untuk mencari data klien yang memiliki tombol cari, reset data, cetak, menambahkan data klien, dan kembali ke halaman home administrasi. Tombol cetak berfungsi untuk mencetak laporan daftar data klien.

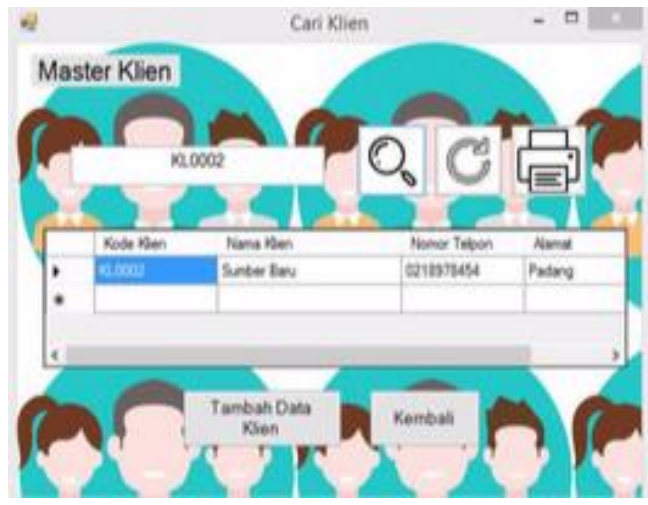

Gambar 8. Halaman cari klien

Pada Gambar 9, data klien yang dapat diisi ialah nama klien, nomor telpon, alamat. Untuk kode klien akan otomatis keluar pada halaman ini, setelah sudah terisi semua klik simpan untuk menyimpan ke dalam database dan juga akan terdapat pada data grid view.

Untuk melakukan pengubahan atau penghapusan data klien, klik salah satu data pada data grid view maka data akan keluar secara otomatis pada setiap field. Tombol reset akan menghapus seluruh input yang telah dilakukan, sedangkan tombol kembali berfungsi untuk mengembalikan user ke halaman cari klien.

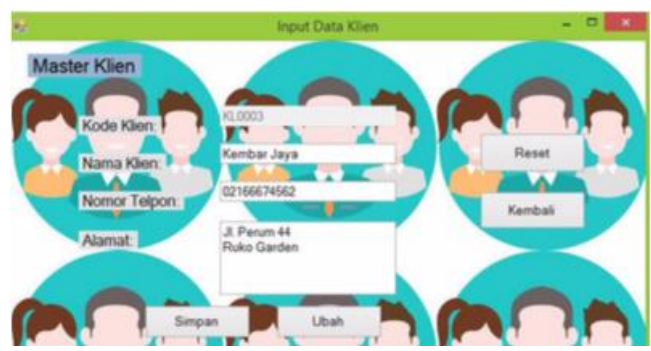

Gambar 9. Halaman input data klien
Gambar 10 menunjukkan halaman mencari DO dengan memasukkan salah satu dari nomor DO, kode klien, nama klien, nomor telepon, ataupun alamat. Tombol cetak akan menghasilkan laporan DO. Gambar 11 menunjukkan halaman untuk mengunggah data DO.



Gambar 10. Halaman cari DO



Gambar 11. Halaman unggah data DO

Pada gambar 12, halaman input data PL, yang dapat diisi yaitu nomor DO dipilih sesuai yang sudah diinput sebelumnya, tanggal, dengan memilih kode klien akan keluar secara otomatis nama klien, nomor telpon, dan alamat, tanggal keberangkatan, tujuan, dan kode kapal dengan nama kapal.

Tombol Isi data barang akan ke halaman selanjutnya gambar 13 sedangkan tombol reset untuk menghapus seluruh input secara otomatis pada field, dan tombol batal akan kembali ke halaman cari PL.

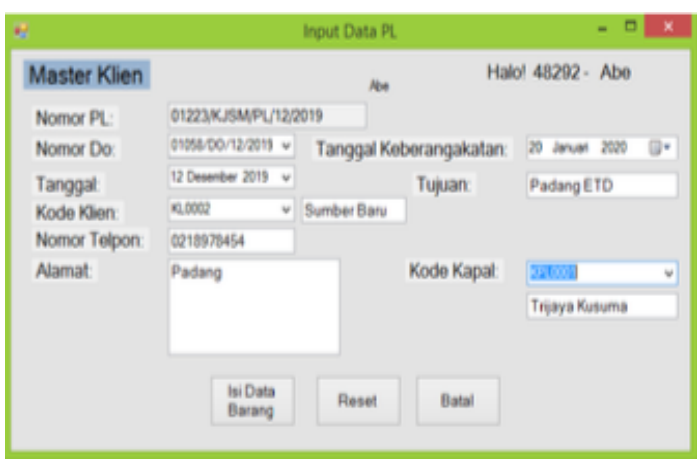

Gambar 12. Halaman input data PL

Gambar 13 merupakan halaman untuk menginput data barang yang dimuat. Dengan memasukkan jumlah barang, memilih nama barang, tempat muat, dan nomor SJ. Untuk 
field jumlah berat akan keluar otomatis saat klik tombol hitung.

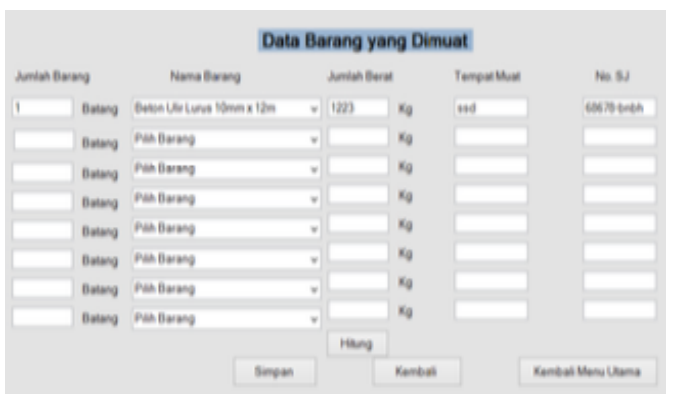

Gambar 13. Halaman input data barang PL

Gambar 14 menunjukkan halaman cari faktur dengan memasukkan salah satu dari nomor faktur, kode klien, nama klien, nomor telpon, atau pun alamat. Selanjutnya pada Gambar 15 menunjukkan halaman input data faktur untuk melakukan pencatatan.

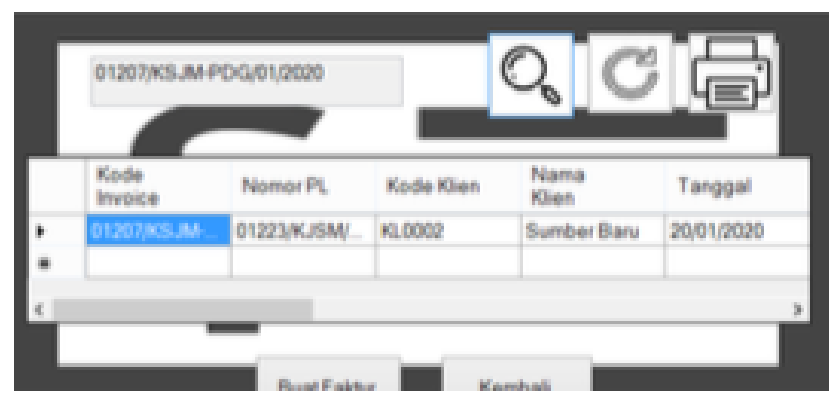

Gambar 14. Halaman cari faktur

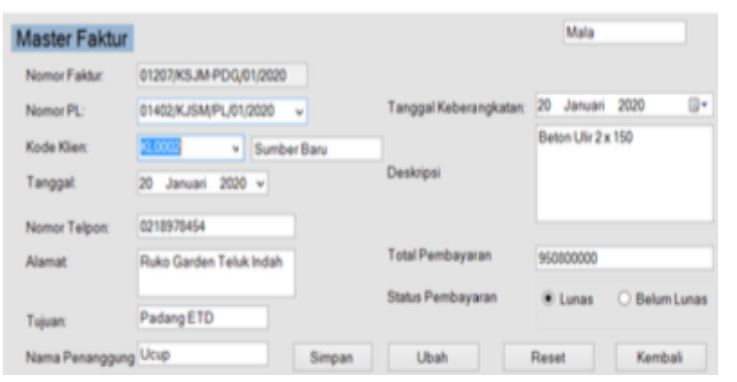

Gambar 15. Halaman input faktur

Gambar 16 menunjukkan halaman untuk melakukan pengubahan pada status pembayaran.

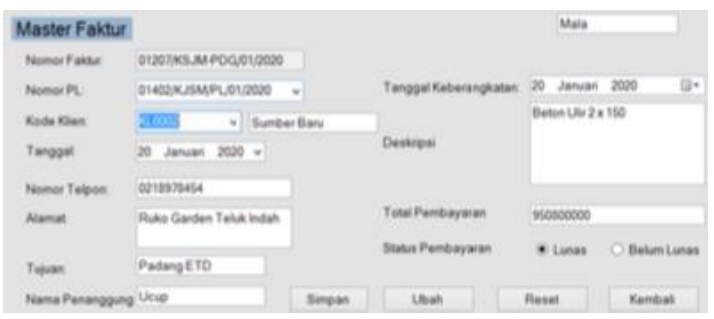

Gambar 16. Halaman Status Pembayaran

\section{B. Hasil Pengujian Aplikasi}

Berdasarkan aplikasi pengelolaan dokumen pada PT KSJM, pengujian dilakukan oleh pimpinan dan bagian administrasi PT KSJM dengan menggunakan teknik UAT. Pembagian modul pengujian dengan kode nomor untuk setiap skenario dari modul tersebut dilakukan sebagai identifikasi terhadap bagian pengujian yang lebih jelas dan dapat dipahami dengan mudah. Pembagian tahapan modul pengujian yang dilakukan dapat dilihat Tabel I.

TABEL I

TAHAPAN MODUL PENGUJIAN

\begin{tabular}{|l|l|l|}
\hline \multicolumn{1}{|c|}{ Nama Modul } & Kode Skenario & \multicolumn{1}{|c|}{ Keterangan } \\
\hline Modul Login & L & $\begin{array}{l}\text { Login dengan } \\
\text { berbagai tipe } \\
\text { pengguna }\end{array}$ \\
\hline Modul Klien & DK & $\begin{array}{l}\text { Melakukan input } \\
\text { data klien }\end{array}$ \\
\hline $\begin{array}{l}\text { Modul Delivery } \\
\text { Order }\end{array}$ & DO & $\begin{array}{l}\text { Melakukan unggah } \\
\text { data DO }\end{array}$ \\
\hline Modul Packing List & PL & $\begin{array}{l}\text { Melakukan input } \\
\text { data barang yang } \\
\text { dimuat }\end{array}$ \\
\hline Modul Faktur & FR & $\begin{array}{l}\text { Melakukan } \\
\text { pembuatan faktur }\end{array}$ \\
\hline Status Pembayaran & SP & $\begin{array}{l}\text { Melakukan } \\
\text { perubahan status } \\
\text { pembayaran }\end{array}$ \\
\hline Modul Kapal & KP & $\begin{array}{l}\text { Melakukan } \\
\text { pembuatan data } \\
\text { kapal }\end{array}$ \\
\hline
\end{tabular}

TABEL III

HASIL PENGUJIAN KESELURUHAN MODUL

\begin{tabular}{|l|l|l|l|l|}
\hline \multicolumn{1}{|c|}{$\begin{array}{c}\text { Nama } \\
\text { Modul }\end{array}$} & $\begin{array}{c}\text { Kode } \\
\text { Skenario }\end{array}$ & $\begin{array}{c}\text { Jumlah } \\
\text { Skenario }\end{array}$ & $\begin{array}{c}\text { Jumlah } \\
\text { Kesesuaian }\end{array}$ & $\begin{array}{c}\text { Jumlah } \\
\text { Ketidak- } \\
\text { sesuaian }\end{array}$ \\
\hline $\begin{array}{l}\text { Modul } \\
\text { Login }\end{array}$ & L & 14 & 14 & 0 \\
\hline $\begin{array}{l}\text { Modul } \\
\text { Klien }\end{array}$ & DK & 12 & 12 & 0 \\
\hline $\begin{array}{l}\text { Modul } \\
\text { Delivery } \\
\text { Order }\end{array}$ & DO & 10 & 10 & 0 \\
\hline $\begin{array}{l}\text { Modul } \\
\text { Packing } \\
\text { List }\end{array}$ & PL & 11 & 11 & 0 \\
\hline $\begin{array}{l}\text { Modul } \\
\text { Faktur }\end{array}$ & FR & 7 & 7 & 0 \\
\hline $\begin{array}{l}\text { Modul } \\
\text { Status } \\
\text { Pembayaran }\end{array}$ & SP & 9 & 9 & 0 \\
\hline $\begin{array}{l}\text { Modul } \\
\text { Kapal }\end{array}$ & KP & 12 & 12 & 0 \\
\hline $\begin{array}{l}\text { Total } \\
\text { Skenario }\end{array}$ & & 75 & 75 & 0 \\
\hline $\begin{array}{l}\text { Total } \\
\text { Persentase }\end{array}$ & & $100 \%$ & 0 \\
\hline
\end{tabular}

Berdasarkan hasil dari keseluruhan pengujian modul dari aplikasi pengelolaan dokumen (lihat Tabel II), didapatkan hasil $100 \%$ untuk jumlah pengujian yang sesuai dan $0 \%$ jumlah pengujian yang tidak sesuai dari 75 skenario pengujian yang telah dilakukan, sehingga dapat diketahui bahwa pengujian tidak menemukan kesalahan sistem dan dapat berfungsi sesuai seperti yang diinginkan. 
Pengujian dilakukan oleh peneliti dengan menggunakan tiga tipe user sesuai dengan skenario pengujian pada semua modul. Admin dapat mengakses keseluruhan halaman klien, DO, PL, Invoice, dan Kapal di mana hampir setiap fungsi yang dijalankan oleh Admin dibandingkan tipe user lainnya adalah sama, sehingga pengujian dengan perwakilan tipe user Admin merupakan keputusan terbaik untuk efisiensi terhadap waktu pengujian.

\section{KESIMPULAN}

Berdasarkan hasil pengujian aplikasi pengelolaan dokumen berbasis desktop pada PT KSJM, maka diperoleh beberapa kesimpulan, yaitu:

1. Aplikasi pengelolaan dokumen yang dibuat berhasil menyimpan unggahan DO, pengentrian data barang yang akan dimuat, pembuatan dan pencetakan faktur.

2. Aplikasi pengelolaan dokumen yang dibuat berhasil melakukan pengentrian data barang yang akan dimuat, pembuatan dan pencetakan faktur.

3. Aplikasi pengelolaan dokumen yang dibuat berhasil membuat faktur dan pencetakan faktur.

4. Aplikasi pengelolaan dokumen yang dibuat berhasil dalam pengujian yang dilakukan dengan menggunakan teknik UAT.

5. Aplikasi pengelolaan dokumen yang dibuat berhasil menyediakan informasi mengenai daftar nama klien dan nama kapal.

\section{DAFTAR PUSTAKA}

[1] P. S. Hasugian, "Perancangan Website Sebagai Media Promosi Dan Informasi," J. Inform. Pelita Nusant., vol. 3, no. 1, pp. 82-86, 2018.

[2] S. P. Palembang, "APLIKASI PENGOLAHAN DATA BONGKAR MUAT BARANG,” vol. 5, no. 3, pp. 201-211, 2015.

[3] E. Yulianti, G. P. Destriana, and Sukemi, "Sistem Informasi Pengiriman Barang Pada PT. Vira Surya Utama Palembang," J. Ilm. Inform. Glob., vol. 09, no. 01, pp. 7-13, 2018.

[4] C. Agustina, "Sistem Informasi Perusahaan Ekspedisi Muatan Kapal Laut Pada PT. Tirang Jaya Samudera Semarang," J. Bianglala Inform., vol. 3, no. 1, pp. 1-9, 2015.

[5] H. Sefriani, E. Hernawati, and F. A. Tridallestari, "Aplikasi Ekspedisi Barang Web (Studi Kasus Pada PT Hasanah Multiguna Expres),"vol. 3, no. 2, pp. 986-994, 2017.

[6] A. A. Sofyan and W. D. Astary, "Aplikasi Pengolahan Data Delivery Order di PT. Sinarmonas Industries," J. Sisfotek Glob., vol. 4, no. 1, pp. 48-52, 2014.

[7] R. Willsher and R. Willsher, "Packing List," in Export Finance, 1995.

[8] P. F. Johnson and A. E. Flynn, Purchasing and Supply Management, 15th ed. McGraw-Hill Education, 2015.

[9] A. Dennis, B. H. Wixom, and D. Tegarden, System Analysis and Design: An object-oriented approach with UML, 5th ed. 2015.

[10] P. M. Wallace, Introduction to Information Systems, Fourth. Pearson, 2019.

[11] S. Tilley, Systems Analysis and Design, 12th ed. Cengage Learning, 2019.

[12] K. C. Laudon and J. P. Laudon, Management Information System, 14th ed. Pearson, 2016.

[13] S. White, "Introduction to BPMN," IBM Coop., 2004.

[14] J. Watkins, S. Mills, J. Watkins, and S. Mills, "User Acceptance Testing," in Testing It, 2011.

[15] W. W. Royce, "Managing the Development of large Software Systems," Ieee Wescon, no. August, pp. 1-9, 1970. 